Luton, UK. ${ }^{6}$ Basildon and Thurrock University Hospitals NHS Foundation Trust, Basildon, UK. ${ }^{7}$ Queen Elizabeth Hospital King's Lynn NHS Foundation Trust, King's Lynn, UK. ${ }^{8}$ James Paget University Hospitals NHS Foundation Trust, Great Yarmouth, UK. ${ }^{9}$ Peterborough and Stamford Hospitals NHS Foundation Trust, Peterborough, UK. ${ }^{10}$ West Suffolk Hospitals NHS Foundation Trust, Bury St Edmunds, UK. ${ }^{11}$ Mid Essex Hospital Services NHS Trust, Chelmsford, UK. ${ }^{12}$ MRC Biostatistics Unit, Institute of Public Health, University of Cambridge, Cambridge, UK.

${ }^{13}$ These authors contributed equally.

Correspondence: Stefan J. Marciniak, Cambridge Institute for Medical Research, Hills Road, Cambridge CB2 0XY, UK. E-mail:sjm20@cam.ac.uk

Received: June 272014 | Accepted after revision: Feb 032015 | First published online: March 182015

Support statement: The study was funded by the East Anglian Thoracic Society. M.Z. Nikolic is a Wellcome Trust PhD Programme for Clinicians Fellow at the University of Cambridge. S.J. Marciniak is a Medical Research Council Senior Clinical Fellow. J. Wason is funded by the Cambridge Biomedical Research Centre. Funding information for this article has been deposited with FundRef.

Conflict of interest: None declared.

\title{
References
}

1 Gupta D, Hansell A, Nichols T, et al. Epidemiology of pneumothorax in England. Thorax 2000; 55: 666-671.

2 Baumann MH, Strange C, Heffner JE, et al. Management of spontaneous pneumothorax: an American College of Chest Physicians Delphi consensus statement. Chest 2001; 119: 590-602.

3 MacDuff A, Arnold A, Harvey J, et al. Management of spontaneous pneumothorax: British Thoracic Society Pleural Disease Guideline 2010. Thorax 2010; 65: Suppl. 2, ii18-ii31.

4 Kelly AM, Druda D. Comparison of size classification of primary spontaneous pneumothorax by three international guidelines: a case for international consensus? Respir Med 2008; 102: 1830-1832.

5 Andrivet P, Djedaini K, Teboul JL, et al. Spontaneous pneumothorax. Comparison of thoracic drainage vs immediate or delayed needle aspiration. Chest 1995; 108: 335-339.

6 Noppen M, Alexander P, Driesen P, et al. Manual aspiration versus chest tube drainage in first episodes of primary spontaneous pneumothorax: a multicenter, prospective, randomized pilot study. Am J Respir Crit Care Med 2002; 165: $1240-1244$.

7 Hooper C, Maskell N, BTS Audit Team. British Thoracic Society national pleural procedures audit 2010. Thorax 2011; 66: 636-637.

8 Brims FJ, Maskell NA. Ambulatory treatment in the management of pneumothorax: a systematic review of the literature. Thorax 2013; 68: 664-669.

9 Massongo M, Leroy S, Scherpereel A, et al. Outpatient management of primary spontaneous pneumothorax: a prospective study. Eur Respir J 2014; 43: 582-590.

\section{Lung cancer screening feasibility in Australia}

\section{To the Editor:}

The National Lung Screening Trial (NLST) reported a 20\% relative reduction in lung cancer-specific mortality using low-dose computed tomography (LDCT) screening [1]. US Preventative Services Task Force modelling [2] illustrates the potentially large benefits of screening, yet nationwide population-based screening has not been adopted. Controversial issues include high false positivity, and uncertain cost-effectiveness and relative applicability to different settings and countries [3-6]. The Queensland Lung Cancer Screening Study (QLCSS) is the first study to assess NLST screening protocol feasibility in Australia.

QLCSS applied the NLST protocol with two modifications: age eligibility was changed from 55-74 years to 60-74 years; and minimum lung function (forced expiratory volume in $1 \mathrm{~s} \geqslant 50 \%$ predicted) was required. Smoking $(\geqslant 30$ pack-years, current or quit within the past 15 years) and general health requirements were identical $[1,7]$.

Volunteers received a baseline and two annual incidence scans ( $\mathrm{T}_{0}, \mathrm{~T}_{1}$ and $\mathrm{T} 2$, respectively). Baseline scans were considered positive if one or more nodules $\geqslant 4 \mathrm{~mm}$ diameter were detected; incidence scans were considered positive if one or more new nodules of any size was detected, or a previously identified nodule 
demonstrated growth. Suspicious non-nodule findings also constituted a positive scan. Recruitment began in December 2007; baseline scans were completed by December 2010. Participants were followed for 5 years; the dataset was censored on September 18, 2014. Exact confidence intervals assumed a Poisson distribution.

256 (26.7\%) out of 960 individuals enquiring about enrolment received baseline scans. Of those who did not go on to enrol (i.e. receive a baseline computed tomography (CT) scan): 256 (36\%) either failed to return the initial paperwork or declined to enrol; 182 (26\%) did not fulfil smoking eligibility criteria; 94 (13\%) fell outside the eligible age range (eligible age range was always mentioned in advertisements); 92 (13\%) were ineligible due to medical comorbidity; and 27 (4\%) had had a CT of the chest within the prior 18 months. Only four $(0.6 \%)$ were ineligible because of poor spirometry. $46(7 \%)$ were ineligible for other various reasons and three $(0.4 \%)$ had missing data. Baseline characteristics are detailed in table 1. 256 (100\%), 239 (93\%) and 233 (96\%) eligible participants completed T0, T1 and T2, respectively. Four (1.6\%) participants without lung cancer died; 12 (4.7\%) withdrew before the planned 5-year follow-up; 154 (60.2\%) participants completed follow-up; and 72 (28.1\%) remain under active follow-up. 14 (5.5\%) participants were diagnosed with lung cancer. Median follow-up was 1825 days (5 years); total follow-up was 1159 person-years.

128 (50\%), 88 (37\%) and 99 (42\%) participants had positive scans at T0, T1 and T2, respectively. Excluding nodules $<4 \mathrm{~mm}$ diameter, positive scans occurred in $128(50 \%), 21(9 \%)$ and $26(11 \%)$, respectively. 17 (6.6\%) out of 256 participants had one or more invasive diagnostic procedures. 3.5\% of positive scans resulted in CT fine needle aspirate (FNA), or 151 procedures per 10000 scans (95\% CI 75-270); 2.9\% underwent bronchoscopy, or 124 procedures per 10000 scans (95\% CI 57-235). For benign disease, rates were 27 and 14 per 10000 scans respectively. There were no surgical procedures for benign disease. Two participants with lung cancer suffered pneumothorax following CT-FNA; one required intercostal tube drainage.

Five $(2.0 \%)$ cancers were diagnosed at $\mathrm{T} 0$, three $(1.3 \%)$ at $\mathrm{T} 1$, four $(1.7 \%)$ at $\mathrm{T} 2$ and two in the follow-up (nonscreening) phase. All cancers were $\geqslant 4 \mathrm{~mm}$ diameter when first detected. The proportion of true positive scans was $3.9 \%, 3.4 \%$ and $4.0 \%$ at $\mathrm{T}_{0}, \mathrm{~T}_{1}$ and $\mathrm{T} 2$, respectively. Lung cancer incidence was 121 per 10000 person-years follow-up (95\% CI 66-203). 12 screen-detected cancers in 728 screening LDCTs equates to 165 per 10000 scans (95\% CI 85-288) or one cancer per 60 screening scans.

$10(83.3 \%)$ out of 12 screened cancers were adenocarcinoma, one was squamous cell carcinoma and one non-small cell lung cancer not otherwise specified. One small cell lung cancer (stage IIIB) was diagnosed 18 months after a negative T2 scan and one adenocarcinoma (stage IA) was diagnosed from a ground-glass opacity tracked for 5.6 years after baseline.

10 out of 12 screen-detected lung cancers were stage I-II. T0 yielded the highest proportion of stage IA tumours (four out of five), whereas $\mathrm{T}_{1}$ and $\mathrm{T} 2$ scans had one stage IA tumour out of three and two stage

\begin{tabular}{|c|c|c|}
\hline Characteristic & QLCSS & NLST LDCT arm \\
\hline Subjects $\mathrm{n}$ & 256 & 26723 \\
\hline Males & $171(66.8)$ & 15770 (59.0) \\
\hline Age years median & 64.5 & 60.0 \\
\hline $55-59$ years & $1(0.4)$ & $11440(42.8)$ \\
\hline $60-64$ years & 139 (54.3) & $8170(30.6)$ \\
\hline $65-69$ years & $90(35.2)$ & 4756 (17.8) \\
\hline 70-74 years & $26(10.2)$ & 2352 (8.8) \\
\hline Current smokers & $121(47.3)^{f}$ & 12869 (48.2) \\
\hline Smoking pack-years & $55(25-235)$ & $48(18-295)$ \\
\hline Duration of smoking years & $44(23-59)$ & $43(12-69)$ \\
\hline Airflow limitation on spirometry ${ }^{\#}$ & $155(60.5)$ & \\
\hline Airflow limitation mild" & $102(39.8)$ & \\
\hline Self-reported occupational asbestos exposure ${ }^{+}$ & $31(12.1)$ & $1238(4.6)$ \\
\hline White/Caucasian ethnicity & 254 (99.2) & 24289 (90.9) \\
\hline Received tertiary education & 119 (46.5) & 14695 (55.0) \\
\hline Family history of lung cancer ${ }^{\S}$ & $46(18.0)$ & 5815 (21.8) \\
\hline
\end{tabular}

Data are presented as $\mathrm{n}(\%)$ or median (range), unless otherwise stated. LDCT: low-dose computed tomography. " : forced expiratory volume in $1 \mathrm{~s}$ (FEV1)/forced vital capacity ratio <70\%; ${ }^{\text {": }}$ FEV $1 \geqslant 80 \%$ predicted; ": responded "yes" to the question "have you worked with asbestos for 1 year or more?"; $\S_{\text {: }}$ first-degree relative; ${ }^{f}$ : self-reported current smoker or quit $<6$ months prior to enrolment. 
IA tumours out of four, respectively. Nine participants underwent surgical resection and four received concurrent chemoradiation; one with metastatic disease received palliative chemotherapy.

Screening sensitivity and negative predictive value (NPV) were $100 \%$ at each screening round. Specificity was $51.0 \%, 64.0 \%$ and $58.5 \%$ at $\mathrm{T} 0, \mathrm{~T} 1$ and $\mathrm{T} 2$, respectively. Positive predictive value (PPV) was $3.9 \%, 3.4 \%$ and $4.0 \%$, respectively. When nodules $<4 \mathrm{~mm}$ size were excluded, sensitivity, specificity, PPV and NPV improved: $100 \%, 51.0 \%, 3.9 \%, 100 \%$ at $\mathrm{T} 0$, respectively; $100 \%, 92.4 \%, 14.3 \%, 100 \%$ at $\mathrm{T} 1$, respectively; $100 \%, 90.4 \%, 15.4 \%, 100 \%$ at $\mathrm{T} 2$, respectively.

QLCSS recruited an older population with more men, heavier smokers and higher self-reported occupational asbestos exposure than NLST [8] (table 1). This may explain the higher rate of lung cancer in QLCSS (121 versus 65 cases per 10000 person-years in NLST [1]). The rate of self-reported asbestos exposure is relatively high, perhaps influenced by explicit mention of asbestos in our advertisements. However, it no doubt also reflects historically high consumption of asbestos per capita in Australia [9], and extensive use of asbestos in housing stock and public buildings [10]. Furthermore, Brisbane imported and exported asbestos through its port, and two asbestos processing plants operated in Brisbane from the 1930s until 1984 [11].

Screening adherence was high. QLCSS positive scan rates were higher than NLST $(27.3 \%, 27.9 \%$ and $16.8 \%$ at $\mathrm{T} 0, \mathrm{~T}_{1}$ and $\mathrm{T} 2$, respectively [1]); false positive rates were $>95 \%$ in both studies. This reflects differences in definitions (e.g. new/growing nodules $<4 \mathrm{~mm}$ considered positive findings on QLCSS incidence scans). Restricting the definition to nodules $\geqslant 4 \mathrm{~mm}$ results measures closer in accuracy to NLST $[12,13]$ : sensitivity, specificity, PPV and NPV were $93.8 \%, 73.4 \%, 3.8 \%, 99.9 \%$ at To, respectively; $94.4 \%$, $72.6 \%, 2.4 \%, 99.9 \%$ at $\mathrm{T} 1$, respectively; $93.0 \%, 83.9 \%, 5.2 \%, 99.9 \%$ at $\mathrm{T} 2$, respectively. In contrast, a volumetric nodule measurement strategy, as used in the NELSON study, may be able to substantially reduce the false-positive scan rate and the mortality data from this study are eagerly anticipated [14].

Screen-detected cancer distribution by stage was similar to NLST (QLCSS: stage IA 58\%, stage IV $8 \%$; NLST: $52 \%$ and $13 \%$, respectively). Adenocarcinoma predominated. True-positive scan rates $(3.8 \%, 2.4 \%$ and $5.2 \%$ at $\mathrm{T} 0, \mathrm{~T}_{1}$ and $\mathrm{T} 2$, respectively, in NLST [1]), and CT-FNA and bronchoscopy rates for positive scans were similar $(1.8 \%$ and $3.8 \%$, respectively [1]). All participants with stage I cancer underwent surgery, which is equivalent to the $92.5 \%$ reported in NLST LDCT arm [1].

The age-standardised incidence of lung cancer in Australia is lower than in the USA [15], yet we found comparable, even slightly higher, rates of detection by increasing the minimum age by 5 years. Using risk models to select individuals for screening may improve this further [16].

QLCSS demonstrated a degree of "volunteer bias": $49 \%$ of the Australian general population aged 60-74 years are men and 37\% have college education, and QLCSS volunteers were not representative of the racial make-up of modern Australia. How this might influence screening outside a research setting is uncertain, but experience from other cancer screening programmes suggests lower socioeconomic groups and certain ethnic groups are harder to attract.

In conclusion, the QLCSS population demonstrated high rates of lung cancer and a high proportion of false-positive scans reflecting the definition of "positivity". We recognise that these pilot findings are limited by sample size and that more robust estimates of benefits and harms requires a larger, multicentric study. Nevertheless, the magnitude of benefit and harm is consistent with NLST, and we believe this study demonstrates that an NLST-style LDCT screening protocol is feasible in Australia.

$@$ ERSpublications

Low-dose CT screening using the NLST protocol appears feasible in the Australian health setting http://ow.ly/JwtU2

Henry M. Marshall ${ }^{1,2}$, Rayleen V. Bowman ${ }^{1,2}$, John Ayres $^{1}$, Jane Crossin ${ }^{1}$, Melanie Lau ${ }^{1}$, Richard E. Slaughter ${ }^{1,3}$, Stanley Redmond ${ }^{1}$, Linda Passmore ${ }^{1}$, Elizabeth McCaul $^{1}$, Deborah Courtney ${ }^{1}$, Steven C. Leong ${ }^{1,2}$, Morgan Windsor $^{1,4}$, Paul V. Zimmerman ${ }^{1,2}$, Ian A. Yang ${ }^{1,2}$ and Kwun M. Fong ${ }^{1,2}$

${ }^{1}$ The University of Queensland Thoracic Research Centre, The Prince Charles Hospital, Brisbane, Australia. ${ }^{2}$ Dept of Thoracic Medicine, The Prince Charles Hospital, Brisbane, Australia. ${ }^{3}$ Queensland University of Technology, Brisbane, Australia. ${ }^{4}$ Dept of Thoracic Surgery, The Prince Charles Hospital, Brisbane, Australia.

Correspondence: Henry M. Marshall, Dept of Thoracic Medicine, The Prince Charles Hospital, Brisbane, Queensland, 4032, Australia. E-mail: Henry.marshall@health.qld.gov.au

Received: Nov 102014 | Accepted after revision: Feb 09 2015 | First published online: April 022015

Support statement: This study was supported by the Australian National Health and Medical Research Council, a Queensland Smart State grant and The Prince Charles Hospital Foundation. Funding information for this article has been deposited with FundRef. 


\section{References}

1 National Lung Screening Trial Research Team. Reduced lung-cancer mortality with low-dose computed tomographic screening. N Engl J Med 2011; 365: 395-409.

2 de Koning HJ, Meza R, Plevritis SK, et al. Benefits and harms of computed tomography lung cancer screening strategies: a comparative modeling study for the U.S. Preventive Services Task Force. Ann Intern Med 2014; 160: 311-320.

3 Woolf SH, Harris RP, Campos-Outcalt D. Low-dose computed tomography screening for lung cancer: How strong is the evidence? JAMA Intern Med 2014; 174: 2019-2022.

4 Hew M, Stirling RG, Abramson MJ. Should we screen for lung cancer in Australia? Med J Aust 2013; 199: 82-83.

5 Field JK, Smith RA, Aberle DR, et al. International Association for the Study of Lung Cancer computed tomography screening workshop 2011 report. J Thorac Oncol 2012; 7: 10-19.

6 Black WC, Gareen IF, Soneji SS, et al. Cost-effectiveness of CT screening in the national lung screening trial. N Engl J Med 2014; 371: 1793-1802.

7 Marshall HM, Bowman RV, Crossin J, et al. Queensland lung cancer screening study: rationale, design and methods. Int Med J 2013; 43: 174-182.

8 National Lung Screening Trial Research Team. Baseline characteristics of participants in the randomized national lung screening trial. J Natl Cancer Inst 2010; 102: 1771-1779.

9 Lin RT, Takahashi K, Karjalainen A, et al. Ecological association between asbestos-related diseases and historical asbestos consumption: an international analysis. Lancet 2007; 369: 844-849.

10 Park EK, Yates DH, Hyland RA, et al. Asbestos exposure during home renovation in New South Wales. Med J Aust 2013; 199: 410-413.

11 Queensland Government. Asbestos investigation - former plants. www.health.qld.gov.au/asbestos Date last accessed: February, 2015. Date last updated: February 19, 2015.

12 The National Lung Screening Trial Research Team. Results of initial low-dose computed tomographic screening for lung cancer. N Engl J Med 2013; 368: 1980-1991.

13 Aberle DR, DeMello S, Berg CD, et al. Results of the two incidence screenings in the National Lung Screening Trial. N Engl J Med 2013; 369: 920-931.

14 Horeweg N, van der Aalst CM, Vliegenthart R, et al. Volumetric computed tomography screening for lung cancer: three rounds of the NELSON trial. Eur Respir J 2013; 42: 1659-1667.

15 Ferlay J, Soerjomataram I, Ervik M, et al. GLOBOCAN 2012 v1.0, Cancer Incidence and Mortality Worldwide: IARC CancerBase No. 11. http://globocan.iarc.fr Date last accessed: May, 2014.

16 Tammemägi MC, Katki HA, Hocking WG, et al. Selection criteria for lung-cancer screening. N Engl J Med 2013; 368: $728-736$.

\section{Quadriceps muscle fibre dysfunction in patients with pulmonary arterial hypertension}

To the Editor:

Despite improvements in disease targeted therapies, pulmonary arterial hypertension (PAH) is a progressive disease and PAH patients remain symptomatic [1]. Exercise intolerance is one of the main symptoms, which limit PAH patients in their daily life activities. Reduced exercise capacity is generally attributed to right ventricular dysfunction [1]. However, as with other cardiac and pulmonary diseases, PAH patients develop respiratory [2] and peripheral muscle [3,4] weakness, which might also contribute to exercise intolerance. Indeed, exercise training improves exercise capacity in PAH patients and maximal oxygen consumption of PAH patients correlates with the functional decline of peripheral muscle strength $[5,6]$. The underlying cause of the reduction in muscle strength is unclear. Some studies have reported muscle fibre atrophy and a shift towards more fast-twitch fatigable fibres in skeletal muscles of PAH patients [3, 7]; however, these are not consistent findings [4, 8].

Recently, we have shown that weakness of the respiratory muscles in PAH patients [8] and in pulmonary hypertension rats [9] is, at least partly, caused by impaired contractility of the sarcomeres, the smallest contractile units in muscle. Whether sarcomere contractility is also affected in peripheral muscles of PAH patients is yet unknown. Physical activity declines in $\mathrm{PAH}$ patients and muscle disuse is known to affect 